\title{
WISATA INTERAKTIF RAMAH LINGKUNGAN
}

\author{
Reza Tanikara ${ }^{1)}$, Franky Liauw ${ }^{2)}$ \\ 1) Program Studi S1 Arsitektur, Fakultas Teknik, Universitas Tarumanagara, rezatanikara@hotmail.com \\ 2) Program Studi S1 Arsitektur, Fakultas Teknik, Universitas Tarumanagara, frankyl@ft.untar.ac.id
}

\begin{abstract}
Abstrak
Pertumbuhan jumlah pengguna sosial media dalam waktu singkat telah meningkat sangat pesat terutama di kota urban seperti Jakarta. Kurangnya interaksi masyarakat dengan alam dapat mengancam kestabilan kesehatan mental masyarakat, rendahnya interaksi tersebut antara lain dikarenakan kondisi fasilitas wisata ekologi yang ada masih kurang. Menghadapi permasalahan di atas, penulis mengusulkan pembangunan wisata interaktif ramah lingkungan yang ingin menggabungkan antara manusia dengan alam. Architourisme merupakan topik penting yang diangkat untuk membantu menyelesaikan permasalahan wisata kota. Pendekatan ini diterapkan pada Waduk Ria-Rio, yang merupakan salah satu lahan terbuka hijau terbesar di Jakarta Timur yang bertujuan mengajak masyarakat lebih peduli terhadap lingkungan dengan mengimpilemtasikan hiburan yang interaktif dan menyenangkan. Maka penulis menambahkan fungsi wisata dalam bidang edukasi, resort, dan interaksi. Fasilitas akan berisi ruang yang dibutuhkan pengunjung yang ingin berinteraksi langsung dengan alam baik flora maupun fauna. Sehingga penulis menghasilkan ide solusi berupa fasilitas wisata ekologi yang terintegrasi dengan alam. Fasilitas wisata akan menggunakan konsep alami yang bisa dirasakan oleh pengunjung dari segi fungsi dan komposisi massa.
\end{abstract}

Kata kunci: arsitektur turisme, ekologi, interaktif, ramah lingkungan.

\begin{abstract}
The growth in the number of social media users in a short time has increased very rapidly, especially in urban cities such as Jakarta. The lack of community interaction with nature can threaten the stability of the mental health of the community, the low interaction among others is due to the lack of ecological tourism facilities. Facing the above problems, the authors propose the development of an interactive environmental tourism that wants to combine human and nature. Architourism is an important topic that was raised to help resolve the city's tourism problems. This approach is applied to the Ria-Rio reservoir, which is one of the largest open green space in East Jakarta which aims to encourage people to care more about the environment by implementing interactive and fun entertainments. So the authors add tourism functions in the fields of education, resorts, and interactions. The facility will contain space needed by visitors who want to interact directly with the nature of both flora and fauna. So that the author produces the idea of a solution in the form of ecological tourism facilities that are integrated with nature. Tourist facilities will use natural concepts that can be felt by visitors in terms of function and mass composition.
\end{abstract}

Keywords: architourism, ecology, environmental, interactive.

\section{PENDAHULUAN}

Ketika berbicara tentang wisata di dunia modern, teknologi dan dunia media sosial merupakan esensi yang penting dari turisme. Media sosial seperti instagram dan facebook telah membuat dunia begitu mudah untuk diakses. Jakarta merupakan satu dari sepuluh kota yang paling sering di "tag" atau dititik lokasikan di dunia, jatuh pada peringkat nomor 8 . Selain memberikan informasi secara mudah sosial media juga memiliki dampak negatif kepada kesehatan mental manusia, khususnya dalam kemampuan untuk berinteraksi dengan sesama, ada setidaknya 6 dampak negatif yang disebabkan oleh sosial media, seperti insecurity (tidak pede), jealousy (iri), addiction (ketagihan) yang dapat menjuru ke penyakit-penyakit mental yang lebih serius seperti depresi, anxiety, skizofrenia, dan sebagainya. Tetapi sebagai manusia 
modern dunia cyber tidak dapat dilepaskan dari kehidupan sehari-hari .

Interaksi manusia dengan alam menjadi salah satu hal yang penting dalam menjaga kesehatan mental manusia modern. Dengan pembahasan tadi, dapat disimpulkan bahwa wisata yang memungkinkan manusia berinteraksi dengan lingkungannya, khususnya lingkungan alam ,sangat dibutuhkan di dalam kota metropolis seperti Jakarta. Belum lagi dengan kondisi Jakarta yang sekarang mulai kekurangan lahan, tanah luas yang akan dikembangkan menjadi habitat alami bukanlah sesuatu yang dapat terwujud dalam konteks urban dan metropolis.

Ide Interactive Environmental Tourism diangkat untuk menjawab isu-isu yang ada di kota metropolitan Jakarta. Institusi ini selain menjadi destinasi rekreasi hijau di kota Jakarta, juga memberikan kesadaran akan kepentingan kesehatan mental penduduk kota melalui interaksi manusia dengan lingkungannya, maupun dengan sesama.

Dari identifikasi masalah yang dijabarkan di atas, maka dapat dirumuskan beberapa masalah yang ada menjadi bahan pembahasan pada proyek ini. Berikut ini merupakan rumusan masalahnya yaitu:

- Fasilitas penunjang apa yang ada pada pusat wisata yang dapat membantu menjaga stabilitas mental pengunjung?

- Atraksi ekologis apa yang dapat menarik wisatawan sehingga menimbulkan interaksi antar manusia dengan alam maupun dengan sesamanya?

- Apa yang dapat mendorong masyarakat Jakarta untuk mengunjungi atraksi hijau? Proyek fasilitas yang akan dirancang ini diharapkan dapat mencapai tujuannya yaitu:

- Menyadarkan masyarakat Jakarta akan pentingnya interaksi manusia dengan alam ataupun sekitarnya guna membantu stabilitas kesehatan mental penduduk Jakarta.

- Meningkatkan intensi dalam berinteraksi sosial.

- Menghadirkan hiburan untuk relaksasi pikiran untuk melupakan kesibukan kerja sejenak.

- Mendekatkan dan mengenalkan kembali manusia dengan alam.

\section{KAJIAN LITERATUR Wisata Ekologi}

Menurut KBBI pengertian wisata adalah bepergian secara bersama-sama dengan tujuan untuk bersenang-senang, menambah pengetahuan, dan lain-lain. Selain itu juga dapat diartikan sebagai bertamasya atau piknik. Sedangkan menurut UU RI No. 10 th 2009, wisata dikenal sebagai kegiatan perjalanan yang dilakukan manusia baik perorangan maupun kelompok untuk mengunjungi destinasi tertentu dengan tujuan rekreasi, mempelajari keunikan daerah wisata, pengembangan diri ,dan sebagainya dalam waktu yang singkat atau sementara waktu.

Ekologi adalah ilmu yang mempelajari interaksi antara organisme dengan lingkungannya dan yang lainnya. Berasal dari kata Yunanioikos (habitat) dan logos (ilmu). Ekologi diartikan sebagai ilmu yang mempelajari baik interaksi antar makhluk hidup maupun interaksi antara makhluk hidup dan lingkungannya. Istilah ekologi pertama kali dikemukakan oleh Ernst Haeckel (1834 - 1914). Dalam ekologi, makhluk hidup dipelajari sebagai kesatuan atau sistem dengan lingkungannya.Menurut Miller (1975) ekologi adalah suatu ilmu mengenai hubungan timbal balik diantara organisme serta sesamanya dan juga dengan lingkungannya. Ekologi memiliki prinsip-prinsip yaitu interaction (interaksi), interdependance (saling ketergantungan), harmony (keharmonisan), dan sustainability (kemampuan berkelanjutan).

Dari definisi-definisi tersebut bisa disimpulkan bahwa wisata ekologi adalah kegiatan perjalanan ke destinasi tertentu untuk mempelajari atau mengamati interaksi antar makhluk hidup maupun interaksi antara makhluk hidup dan lingkungannya 


\section{Etika Lingkungan}

Etika lingkungan adalah perbuatan apa yang dinilai baik untuk lingkungan dan apa yang tidak tidak baik bagi lingkungan. Etika lingkutan bersumber pada pandangan seseorang tetang lingkungan.

\section{- Antroposentrisme}

Antroposentrisme adalah teori etika lingkungan yang memandang manusia sebagai pusat dari sistem alam semesta. Manusia dan kepentingannya dianggap yang paling menentukan dalam tatanan ekosistem dan dalam kebijakan yang diambil dalam kaitan dengan alam. Alam hanya dilihat sebagai obyek, alat dan sarana bagi pemenuhan kebutuhan dan kepentingan manusia. Alam hanya alat bagi pencapaian tujuan manusia. Alam tidak mempunyai nilai pada dirinya sendiri.

- Biosentrisme dan Ekosentrisme

Pada biosentrisme, konsep etika dibatasi pada komunitas yang hidup (biosentrism), seperti tumbuhan dan hewan. Sedang pada ekosentrisme, pemakaian etika diperluas untuk mencakup komunitas ekosistem seluruhnya (ekosentrism).

\section{METODE}

\section{Data Primer}

Observasi. Pengamatan yang dilakukan di lapangan dilakukan pada tanggal 20 September 2018 pada Pk. 13.00-15.00, di Taman Ria Rio. Pengamatan dilakukan kembali pada tanggal 13 Oktober 2018 pada Pk. 15.00-16.00 di Kelurahan Pulo Gadung dan jalan di sekitar terminal Pedongkelan.

\section{Data Sekunder}

Data sekunder didapatkan dari buku referensi dan internet untuk pemahaman teori serta komparasi dengan proyek terkait.

Studi Literatur

- Sebagai dasar teoritis untuk membentuk keterhubungan dalam perkotaan.

- Mengetahui standar-standar berkaitan dengan perancangan wisata ekologi.

- Mendapatkan data-data awal tentang proyek terkait.

Studi preseden

- Sebagai perbandingan proyek sejenis.

- Mengetahui program dan kebutuhan ruang proyek sejenis.

\section{DISKUSI DAN HASIL}

Terdapat teminologi seperti tourism architecture dan architecture tourism. Tourism architecture mendeskripsikan banyaknya varian fungsi oleh sebuah karya arsitektur dalam konteks turisme, namun architectural tourism menekankan sebuah karya arsitektur sebagai atraksi utama terjadinya turisme tersebut. Architectural tourism tidak hanya terbatas pada bangunan-bangunan bersejarah saja seperti Eiffel tower di Paris, Colosseum di Roma dan sebagainya, yang kemudian diklasifikasikan sebagai heritage tourism. Architectural tourism juga merangkul bangunan-bangunan kontemporer seperti museum Guggenheim Bilbao, Pompidou di Paris. Lippard (2005) mengatakan bahwa turis cenderung untuk mencari sesuatu yang tua atau yang baru, hal yang diantaranya biasa diabaikan kecuali hal tersebut monumental. Ketika berbicara tentang turisme, tua atau baru tidak begitu menjadi penting namun spektakuler atau tidaknya suatu karya menjadi penarik manusia dalam turisme. Selama karya tersebut spesial, umur dan sejarah mereka kadang tidak menjadi faktor yang mempengaruhi.

Dalam konteks tourisme yang merupakan industri servis, pergerakannya dipengaruhi oleh manusia. Ketika berbicara tentang tourisme, batas-batas tradisional bisa dilupakan. Di muka arsitektur yang spektakuler dan mengundang seperti museum Guggenheim di Bilbao, konsep 
tradisional form follows function sudah tidak bisa mendefisini karya arsitektur sebagai ikon tourisme, namun digantikan dengan apa yang terlihat sebagai function follows form. Dalam turisme, apalagi pada masa modern, bentuk menjadi aspek yang sangat penting dalam mengundang pengunjung. Kalau membicarakan keterkaitan antara turisme dan lingkungan buatan, arsitektur akan selamanya memiliki peran yang penting.

Kalau berbicara tentang tourism yang berarah pada architectural tourism, konteks spasial dan urban tidak dapat terlepaskan. Pastinya turis yang datang untuk melihat suatu karya arsitektur, akan menikmati kota dimana karya itu berada, dari hal-hal seperti akomodasi, transportasi, suasana, dan sebagainya. Melihat bangunan-bangunan yang ada di dalam kota dapat mengindikasikan sejarah, budaya, kekuatan ekonomi dan politik yang ada di tempat tersebut. Dalam usaha untuk transformasi urban, arsitektur kontemporer memiliki peran yang sangat penting sebagai inisiator maupun fasilitator turisme.

Sudah menjadi budaya manusia dari zaman dahulu, berpergian untuk melihat atau mengalami sesuatu yang spektakuler. Hal itu tidak berubah bahkan sampai sekarang. Walaupun dunia media sosial memudahkan orang untuk melihat suatu benda, perasaan ingin mengalami benda itu secara langsung tetap menjadi pendorong terjadinya turisme, Bahkan ketersediaan informasi secara virtual cenderung mendorong orang untuk berpergian.

Pada era digital dimana semua manusia sudah menjadi fotografer dalam konteks pribadi membuat Arsitektur kontemporer memiliki dampak atau pengaruh besar terhadap destinasi urban. Walaupun tujuan turis bervariasi, mayoritas dari mereka dalam pencarian untuk yang fotogenik, karya arsitektur dapat mengamplifikasi perasaan tersebut hingga pengunjung dapat merasakan kepuasan akan pernah mendatangi suatu lokasi. Bahkan sebelum masa digital, manusia selalu terbiasa menceritakan pengalamannya pada orang lain. Memori yang ada secara digital, diunduh secara online mendorong elemen yang penting kepada tourism.

\section{Usulan Tapak}

Sebagai kota yang kekurangan lahan terbuka hijau, Jakarta terancam menjadi salah satu kota yang terputus dari interaksi dengan alam. Tertera dibawah ini peta rencana RTH 20112030. Beberapa atraksi hijau yang tersedia di Jakarta dipetakan dibawah

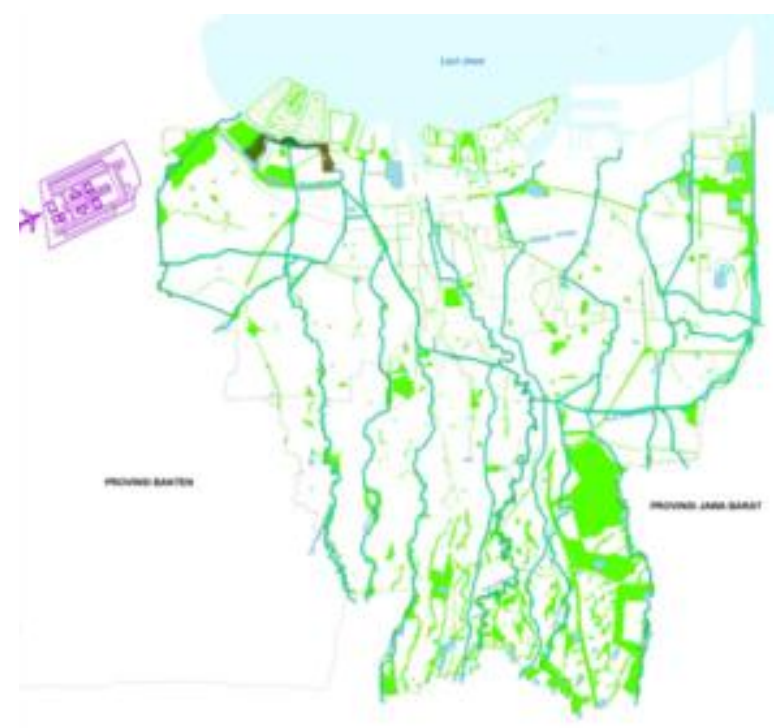

Gambar 1. RTH kota Jakarta

Sumber: Rencana Tata Ruang Wilayah 2011

Diantaranya adalah Taman Wisata Alam Angke, Monas, Ancol, dan Ragunan yang terletak pada Wilayah Adiministratif Kota Jakarta Utara, Jakarta Pusat, dan Jakarta Selatan. Jakarta Timur sebenarnya memiliki potensi sebagai destinasi wisata ekologi yang disarankan. Namun 
melihat kondisi Jakarta Timur kurang berkembang dibanding wilayah lainnya dan lokasi yang dipilih harus strategis dimana area sekitarnya sudah ramai pemukiman dan memiliki akses yang mudah maka salah satu kecamatan yang memiliki kriteria tersebut adalah Pulo Gadung. Kawasan Pulo Gadung memiliki akses langsung kepada Jakarta Utara dan Jakarta Timur.

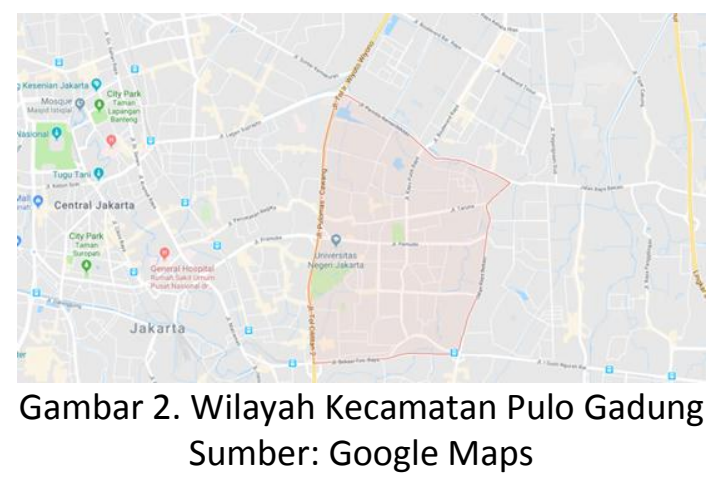

Pulo Gadung dikelilingi oleh ramainya daerah pemukiman mulai dari Cempaka Putih, Kelapa Gading, dan Pulomas. Secara akses ditunjang oleh jalan tol Cempaka Putih dan dikelilingi oleh potensi pengunjung yang berprospek. Kecamatan Kelapa Gading juga termasuk salah satu destinasi rekreasi bagi orang Jakarta walaupun bergerak dalam bidang hiburan atau rekreasi. Kedekatan lokasi ini membuat Kecamatan Pulo Gadung wajib diakses atau dilalui bagi mereka yang datang dari Jakarta Utara, Jakarta Pusat, maupun Jakarta Selatan. Letaknya yang strategis karena terletak di antara salah satu atraksi Jakarta, membuat kecamatan Pulo Gadung berpotensi sebagai lokasi terpilih.

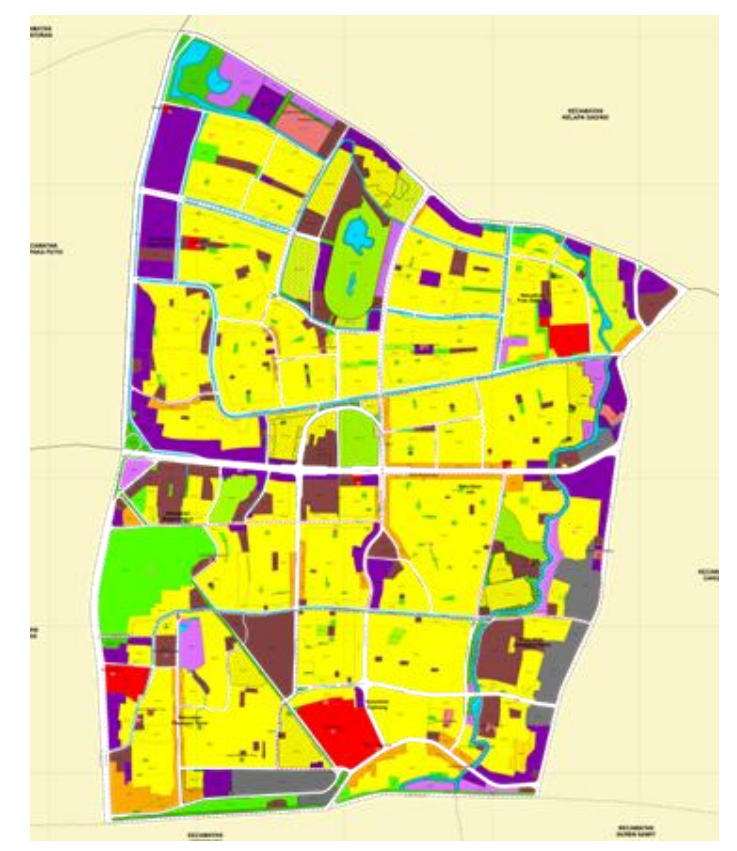

Gambar 3. Rencana Detail Tata Ruang (RDTR) Kecamatan Pulo Gadung Sumber: Dinas Tata Ruang Pemprov. DKI Jakarta

Dari peta RDTR, Waduk Ria Rio menjadi menarik sebagai lokasi yang dapat dikembangkan. Sesuai dengan artikel yang dikeluarkan oleh Kompas, Pemerintah Provinsi DKI Jakarta berencana membangun sebuah taman kota di Waduk Ria Rio, Cakung, Jakarta Timur. Namun, tak seperti taman kota pada umumnya. Pemerintah Provinsi DKI Jakarta sudah dapat melihat potensi lahan ini sebagai objek wisata.

Waduk Ria Rio memiliki lahan tanah yang cukup besar, dengan rencana adanya reklame di 
tengah waduk juga sebagai penangkal banjir dengan teknik terasering. Yang menjadi menarik, Taman Ria Rio terletak tepat didepan dataran air Waduk Ria Rio yang memungkinkan turis untuk melakukan kegiatan fotografi pada bangunan yang akan dikembangkan, selayaknya bangunan architourism yang bisa dinikmati dari dalam maupun dari luar bangunan. Dengan luas lahan 26 hektar, Waduk Ria Rio memiliki potensi sebagai lokasi objek wisata, baik atas air, maupun di tanah yang tersedia yang mewadahi kegiatan wisata.

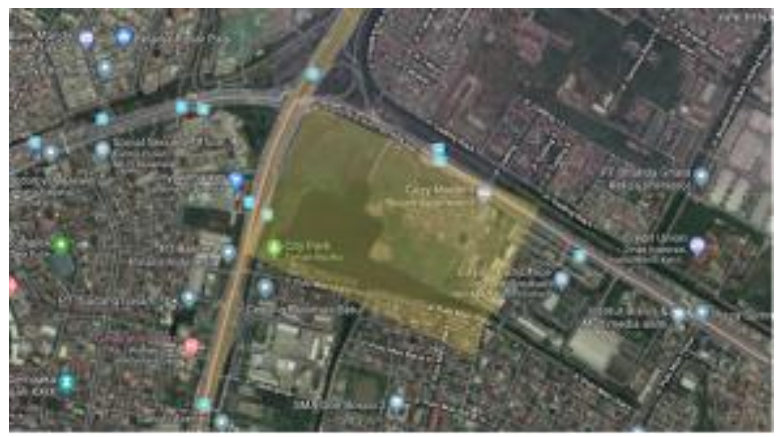

Gambar 4. Usulan Tapak, Waduk Ria-Rio

Sumber: Google Maps

Perhitungan luas daerah perencanaan tapak menurut peruntukan dan intensitas bangunan yang diizinkan oleh RDTR yaitu:

$\begin{array}{ll}\text { KDB } & : 30 \% \times 60.000 \mathrm{~m} 2=18.000 \mathrm{~m}^{2} \\ \text { KLB } & : 4.5 \times 60.000 \mathrm{~m} 2=270.000 \mathrm{~m}^{2} \\ \text { KDH } & : 45 \% \times 60.000 \mathrm{~m} 2=27.000 \mathrm{~m}^{2} \\ \text { KB } & : 24 \\ \text { KTB } & : 40 \% \times 60.000 \mathrm{~m} 2=24.000 \mathrm{~m}^{2} \\ \text { Zona } & : \text { K.1 } \\ \text { Peruntukan } & : \text { Perkantoran, perdagangan, jasa }\end{array}$

\section{Konsep Perancangan}

Konsep dari gubahan massa bangunan didasarkan dari pengalaman eksploratif yang ada di alam. Dimana bangunan dihubungkan oleh ruang luar berupa taman sehingga terjadi integrasi antara bangunan dan juga alam. Hal ini mendorong konsep ekologis yang mau dimunculkan yaitu wisata interaktif terhadap lingkungan. Sebagai strategi desain massa bangunan dibuat banyak dan teripsah-pisah.

Inspirasi bentuk dan fasade dari bangunan juga terinspirasi oleh alam dimana bangunan dimunculkan dengan bentuk organik sehingga terjadi kesan yang alami terhadap bangunan dan bangunan menyatu dengan alam. Tower bangunan merupakan bentukan yang diadaptasi dari pegunungan yang diterjemahkan kedalam bentuk bangunan yang dinamis.

Terkait sistem sirkulasi, dibedakan atas horizontal dan vertikal. Pada sistem sirkulasi horizontal, terdiri atas dua pintu masuk untuk pejalan kaki. Pintu masuk dari taman publik dan juga dari pedestrian Jl. Perintis Kemerdekaan maupun drop off mobil. Pergerakan pengunjung di dalam fasilitas didesain guna menciptakan suasana alami dimana pengunjung dapat dengan mudah mengakses fasilitas namun juga mendapat kesan interaktif dan alamiah selama berada di lintasan luar bangunan.

Sikulasi vertikal (lift) terbagi menjadi 2 yaitu lift penumpang dan lift barang. Lift penumpang terletak pada masing-masing setiap massa bangunan yang berada pada titik-titik yang dekat dengan daerah utilitas. Lift barang berjumlah sebanyak 2 buah, yang langsung berhubungan dengan loading dock. 


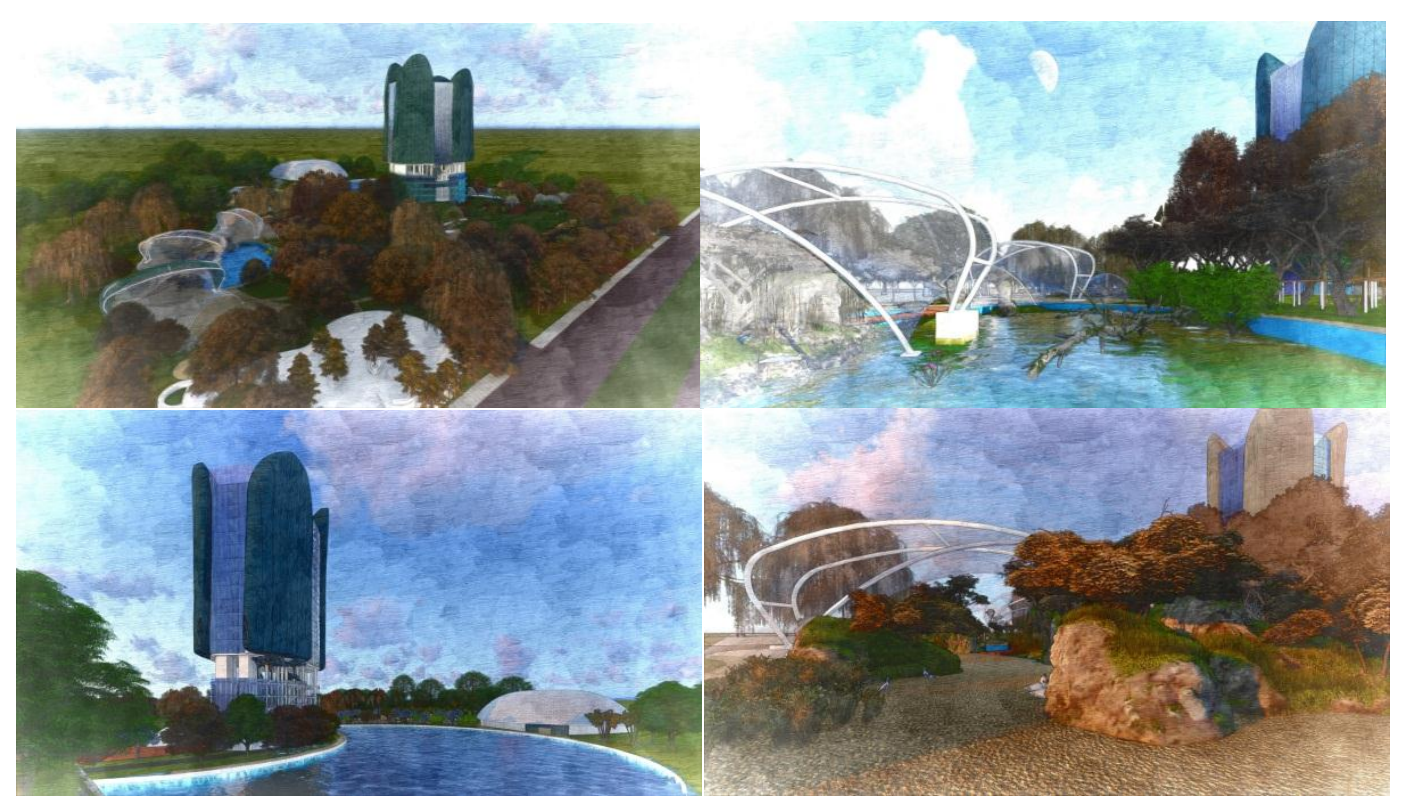

Gambar 5. Gambar Perspektif Eksterior

Sumber: Olahan Penulis, 2018.

\section{KESIMPULAN DAN SARAN}

Setelah melewati proses analisis dan perancangan dari proyek ini, maka dapat diambil beberapa kesimpulan yang menjadi poin-poin penting dari proyek ini. Beberapa kesimpulan dan poin penting diantaranya :

- Wisata Interaktif Ramah Lingkungan diharapkan dapat memberi kesadaran pada masyarakat akan pentingnya Interaksi dengan alam.

- Lokasi tapak yang sebagian besar dikelilingi vegetasi memberikan pengalaman yang ekologis pada pengunjung dengan pencahayaan dan pengudaraan alami.

- Interaksi dengan alam dibutuhkan agar masyarakat tidak terbeban oleh stresor kehidupan urban.

- Area komunal dan ruang terbuka hijau merupakan open space dimana bisa menjadi pusat transisi serta dapat merelaksasikan pikiran sejenak.

- Atraksi-atraksi yang ada dalam fasilitas dapat mendorong masyarakat untuk mendatangi fasilitas hijau.

\section{UCAPAN TERIMA KASIH}

Perkenankan pada kesempatan ini penulis mengucapkan terima kasih kepada pihak-pihak yang telah membatu dalam proses penyelesaian artikel jurnal Stupa ini, yaitu:

- Dosen pembimbing dan Dosen pendamping Tugas Akhir,

- Dosen mata kuliah dan pembimbing lainnya,

- Ketua Program Studi Sarjana Arsitektur, Jurusan Arsitektur dan Perencanaan, Fakultas Teknik, Universitas Tarumanagara

- Ketua Jurusan Arsitektur dan Perencanaan, Fakultas Teknik, Universitas Tarumanagara 


\section{REFERENSI}

Christakis, D., \&Moreno, M. (2009). Trapped in the net: Will internet addiction become a 21st-century epidemic?. Archives Of Pediatrics And Adolescent Medicine, 163(10), 959-960 Lynch, Kevin. (1981). A Theory of Good City Form. United States: The MIT Press.

Lynch, Kevin. (1960). The Image of the City. United States: The MIT Press.

Specth, Jan. (2014). Architectural Tourism. Springer Gabler

The Bilbao effect: how Frank Gehry's Guggenheim started a global craze,

https://www.theguardian.com/artanddesign/2017/oct/01/bilbao-effect-frank-gehry-

guggenheim-global-craze, diakses 20-7-2018

Why Connecting With Nature Elevates Your Mental Health,

https://www.psychologytoday.com/us/blog/the-new-resilience/201801/why-connecting-

nature-elevates-your-mental-health, diakses 28-7-2018

Peta Zonasi Kecamatan Pulo Gadung dan sekitarnya,

http://smartcity.jakarta.go.id/, diakses 12-8-2018

Austria Pavillion Milan Expo 2015,

https://www.archdaily.com/629540/austria-pavilion-nil-milan-expo-2015-team-breatheaustria?ad_medium=gallery, diakses 23-7-2018

Ecorium of The National Ecological institute,

https://www.archdaily.com/423255/ecorium-of-the-national-ecological-institute-nbbj-in-

collaboration-with-samoo-architects-and-engineers-grimshaw-

architects?ad_medium=gallery, diakses 23-7-2018

Gardens by the Bay,

https://www.archdaily.com/254471/gardens-by-the-bay-grant-associates, diakses 23-7-2018 